\title{
EL GOBERNADOR LAGRAÑA DECIDIDO OBRERO DEL MITRISMO
}

\author{
The Governor Lagraña was a Faithful Worker of Mitrism
}

\section{Juan Martín Alvarado}

\section{Resumen}

La provincia de Corrientes adhirió de manera "espontánea" al liberalismo porteño que se impuso en todo el país luego de la batalla de Pavón. La combinación de elites urbanas y comandantes militares de la campaña provincial permitió conducir este proyecto político prácticamente sin sobresaltos hasta la guerra de la Triple Alianza. Su programa era el de la "invención del progreso" que convertía a la economía en el motor de la historia. El capital y la mano de obra extranjeros volverían productivos nuestros "desiertos". Corrientes estaba muy lejos de ver realizada estas aspiraciones, sin embargo Manuel Ignacio Lagraña que condujo los destinos provinciales entre 1862 y 1865 puso la exigua administración provincial al servicio de la promesa del "adelanto material". El credo liberal se difundió desde las páginas de "El Progreso", diario oficialista, y fue articulado con la realidad por la tarea ímproba de preceptores, jueces de paz y concejales que procuraron llegar al pueblo llano. Esta segunda tarea fue más difícil y sus resultados menos alentadores. Este trabajo procura describir este proceso.

$<$ Corrientes $><$ Mitrismo $>$

\begin{abstract}
The province of Corrientes submitted in a "spontaneous" to the liberalism which was imposed in the whole Country after the battle of Pavón. The combination of the urban elites and military chiefs of the local campaign allowed to lead this Political project almost without any inconvenient until Triple Alianza War. His political Program was "The invention of progress" which became the economy in the motor of history. The capital and foreign workers would make our "deserts" into productive lands. Corrientes was far from seeing finished its aspirations, nevertheless, Manuel Ignacio Lagraña, who led the destinies of the Provence between 1862 and 1865 set the exiguous local administration to the service of the "Material improvement". The liberal ideas were spread from the pages of the official newspaper "The Progress", and were driven with the reality because of the unlikelihood labor of private tutors, judges of pace and city councilmen who tried to reach the lower social class. This second task was easier and its results less motivating. This Work tries to describe this process.
\end{abstract}

$<$ Corrientes $><$ Mitrism $>$ 


\section{Introducción}

En diciembre de 1862 accedía a la primera magistratura correntina Manuel Ignacio Lagraña, cargo que desempeñó por tres años como lo ordenaba la constitución provincial. Hombre de negocios y afiliado al mitrismo correntino dedicó su gestión a procurar el adelanto material y preferir las luchas políticas.

Para detallar los esfuerzos realizados en este sentido, bosquejamos primero el contexto político en el cual le tocó cumplir su mandato. Luego nos enfocamos en los diferentes recursos que utilizó para imponer la premisa de su gobierno. Analizamos así, la prédica del diario oficialista, el rol de la instrucción pública, el trabajo de los jueces de paz y las municipalidades. Por último nos detenemos en el pueblo llano, supuesto beneficiario de esta política, para terminar de indagar sus verdaderos alcances.

\section{El mitrismo correntino}

El 17 de septiembre de 1861 la batalla de Pavón decidió nuestras guerras civiles a favor del liberalismo porteño. Bartolomé Mitre no desaprovechó la oportunidad y logró con el ejército de la provincia de Buenos Aires construir la base de la Argentina unida y liberal. Era el fin del "caudillismo bárbaro y su desierto", había que crear el hombre económico y progresista, el productor, el creador de riquezas. Para ello era necesario la ordenación legal del estado que garantizara normas jurídicas para el buen funcionamiento de los negocios, fomento de la inmigración para poblar los "desiertos", progreso económico facilitado por la inversión extranjera, ferrocarriles que comunicaran las vastas extensiones y promovieran el desarrollo de la actividad agropecuaria y el comercio, y por último, pero no menos importante, la educación pública que instruiría a los habitantes en los ideales del liberalismo. ${ }^{1}$

La provincia de Corrientes no precisó de la ayuda del ejército porteño para adherir a la causa impuesta en Pavón. Una facción política formada como oposición a los gobiernos de Juan Pujol (1852-1859) se sublevó a fines de noviembre de 1861 obligando a dimitir a su sucesor, José María Rolón, tras los acuerdos de Cañada Moreno en diciembre del mismo año. ${ }^{2}$

El grupo revolucionario tenía dos sectores, uno integrado por comandantes militares de la campaña del sur provincial descontentos con las medidas de gobierno, llevadas adelante por Pujol y Rolón, que buscaban someterlos a la autoridad civil y el otro formado por miembros de la elite capitalina que no comulgaban con la política vigente

\footnotetext{
${ }^{1}$ El único liberalismo que se plasmó en Argentina después de Pavón fue el liberalismo económico de A. Smith y D. Ricardo y su afín político el utilitarismo de J. Bentham y J. Mill. Le cupo a la presidencia de Mitre lograr el orden para que medraran los negocios. El senador Nicasio Oroño realizaría el balance de sangre de su mandato: "Desde junio de 1862 hasta igual de 1868, han ocurrido en las provincias 117 revoluciones, habiendo muerto en 91 combates, 4.728 ciudadanos." (RUIZ MORENO, 2000)

2 Firmado por Cayetano Virasoro en representación del gobierno provincial y el jefe de las tropas revolucionarias Coronel Raimundo Reguera, establecía el cese del Gobernador Rolón, la renovación de la legislatura en quince días, el licenciamiento de las tropas y la designación provisoria de un hombre afín a los revolucionarios al frente del ejecutivo, el elegido fue José Pampín. (CASTELLO, 1984)
} 
en la Confederación. Por diferentes razones ambos eran antiurquicistas y solidarios al liberalismo porteño. Les cupo a los militares realizar el esfuerzo del levantamiento y a las elites urbanas capitalizarlo. José Pampín, uno de sus representantes, fue nombrado gobernador para cumplir el período del depuesto. De inmediato la provincia se alineó tras los pasos del gobernador de Buenos Aires, Bartolomé Mitre, entregándole el manejo de las relaciones exteriores. ${ }^{3}$

Una vez en el poder el mitrismo correntino dejó entrever fisuras. La reincorporación del general Nicanor Cáceres ${ }^{4}$ a las milicias provinciales provocó la disconformidad de algunos comandantes militares que se sublevaron en julio de 1862. La represión no se hizo esperar, el 6 de agosto del mismo año los rebeldes fueron derrotados por el propio Cáceres en las cercanías de Curuzú Cuatiá. La mayoría de los comandantes se alinearon al vencedor, los restantes partieron al exilio.

La sucesión de Pampín también fue causa de discordias. El gobernador impuso la candidatura de Manuel Ignacio Lagraña, hecho que suscitó malestar en figuras de la elite urbana. Juan Eusebio Torrent, que había sido su ministro de gobierno hasta mayo de 1862, se quejaba ante el presidente Mitre en noviembre del mismo año:

"Poniendo en ejercicio todos los medios oficiales y empleando la coacción militar más descarada se pretende imponer las candidaturas o del Coronel Reguera o del señor Lagraña, que representan del modo más genuino el imperio del caudillaje personificado en la figura sangrienta del general Cáceres. Estas influencias, universalmente odiadas en toda la provincia, no

\footnotetext{
${ }^{3}$ Desde Corrientes el 11 de enero de 1862 Luciano Torrent escribía al gobernador de Buenos Aires Bartolomé Mitre: "Hoy se ha publicado con gran solemnidad el decreto que verá V. E., por el cual se le inviste a V. E. de las facultades necesarias para la pronta reconstrucción de los poderes nacionales. Los considerandos del decreto están redactados en términos enérgicos, los que manifiestan de un modo muy significativo la actitud franca y decisiva que asume este Gobierno; y debo decir a V. E. que ha hecho buen efecto en esta población despertando en ella la fe y la esperanza de ver reorganizada la Nación, bajo los auspicios de V. E. No dudo que en toda la provincia producirá el mismo entusiasmo recordando al gran partido liberal, que forma la mayoría, los tiempos heroicos de este gran pueblo, cuando con la sangre de sus hijos luchaba por la causa que al fin triunfó en los campos de Pavón." ARCHIVO DEL GENERAL MITRE. Pacificación y reorganización nacional. Después de Pavón. (Conclusión) Bs. As., Biblioteca de "La Nación", 1912. T. XII, p. 59.

${ }^{4}$ Nacido en Curuzú Cuatiá en 1809 en una familia del pueblo llano, inicia su participación en política tomando las armas para luchar contra la tiranía de Rosas en Pago Largo en 1839. Acompaña el levantamiento de los hermanos Madariaga en la década siguiente, pero antes del combate de Vences, en 1847, se pasa al bando de Urquiza. Desde entonces actuará bajo la protección del caudillo entrerriano complicando las gestiones de Pujol que intentaron someter el sur provincial al control administrativo de la capital. Luego de la batalla de Pavón, por sugerencia de Pedro Ferré, Mitre intenta cooptarlo para utilizarlo como contrapeso de Urquiza y lo nombra general del ejército nacional. A partir de entonces se convierte en el caudillo indiscutido del sur provincial y tras la invasión paraguaya de 1865 en el hombre fuerte de la provincia logrando imponer como sucesor del gobernador Lagraña a Evaristo López a fines del mismo año. En 1868 su elegido resulta derrocado por una rebelión liberal con participación del ejército nacional, Cáceres sale en su defensa y es derrotado, debiendo emigrar a Entre Ríos primero y luego a Salto (Uruguay) donde muere en 1870. (BUCHBINDER, 2005.)
} 
pueden señor, prolongar el tiempo de su predominio, sino por la violencia; y de aquí viene que todo el antiguo partido liberal en "masa" con excepción de 'una familia', se han unido para resistirlos" $" 5$

De nada sirvió el vociferado principismo de algunos liberales, Pampín con el respaldo de la "figura sangrienta" de Cáceres ${ }^{6}$ logró que su candidato accediera a la primera magistratura. Bartolomé Mitre fue el árbitro en estas diferencias y sus fallos fueron convalidados o recibieron el visto bueno de Urquiza, cuyo poder todavía era importante en la región. (BUCHBINDER, 2004, pp. 123-124.)

Manuel Ignacio Lagraña, nacido en 1821, era un hombre de gran fortuna personal. No había participado en las luchas contra Rosas, iniciando su carrera política recién en 1856 al ser designado diputado provincial por Curuzú Cuatiá. Una empresa periodística, la fundación del primer diario no oficialista ${ }^{7}$ de la provincia, lo asoció a José Pampín y producto de esta relación llegó a la gobernación el 28 de diciembre de $1862 .{ }^{8}$

El flamante mandatario, a poco de asumir, escribía al presidente de la nación haciéndole una declaración de fe:

"Mis principios son los que proclamaron nuestros ilustres mayores, en mayo de 1810, y al fin triunfaron en Pavón y Cañada Gómez, y por los que esta provincia luchó brazo a brazo tantos años, sacrificó sus mejores hijos. En la obra patriótica que V. E. tiene entre sus manos encontrará en mi un decidido obrero, para que alcance a formar una patria grande y feliz bajo el amparo de nuestro código fundamental". 9

Su intención era dejar de lado las luchas estériles que tanto tiempo habían retrasado el progreso y dedicarse pura y exclusivamente a generar las condiciones que lograran el tan anhelado adelanto material.

Como les sucede a todos los gobernantes, sus intenciones resultaron entorpecidas por algunas contrariedades. En primer lugar, la escasez del erario público, producto

${ }^{5}$ Juan Eusebio Torrent a Bartolomé Mitre. 22-11-1862. ARCHIVO DEL GENERAL MITRE. Presidencia de la República (continuación) Años 1862-1868. Bs. As., Biblioteca de "La Nación”, 1913. T. XXV, p. 187.

6 "Con nuestros amigos trabajamos por la candidatura para gobernador para reemplazarlo a U. por nuestro amigo Don Manuel I. Lagraña y por lo que espero que U. como amigo trabajará también salvo algún otro que usted tuviese, pues el nuestro ya se lo participo, mas espero que U. me diga si es de su agrado..." Carta de Nicanor Cáceres a José Pampín 6-10-1862. Archivo General de la Provincia de Corrientes (en adelante A. G. P. C.) FONDO MANTILLA. Legajo $n^{\circ} 47$ : 1861-1862.

${ }^{7}$ Una imprenta adquirida por José Pampín y Manuel Ignacio Lagraña permitió la edición del diario La Libertad desde 10 de julio de 1860 hasta 10 de enero de 1861. Dirigido por Juan Eusebio Torrent expresó a la oposición del gobierno de José María Rolón. El cuestionamiento de las elecciones legislativas provinciales fueron motivo de su clausura. (CASTELLO, 1984, pp. 401-402.)

${ }^{8}$ A. G. P. C. GÓMEZ, Hernán Félix. Diccionario Biográfico. Carpeta no 3, p. 307.

${ }^{9}$ Manuel Ignacio Lagraña a Bartolomé Mitre. 13-01-1863. ARCHIVO GENERAL MITRE. Op. Cit. T. XXV, p. 130. 
de la pérdida de las rentas aduaneras ${ }^{10}$ y su ineficiente reemplazo por la Contribución Directa $^{11}$, situación que procuró solucionar apelando a la venta de tierras y a la solicitud de subsidios nacionales. Sin embargo ambos recursos no impidieron que todos los años de su gestión el déficit presupuestario superará los cálculos gubernamentales. (BUCHBINDER, 2004, pp.137-143) En segundo lugar las rencillas internas, a dos meses de hacerse cargo de la gobernación escribía desilusionado a su amigo Pampín: "Al aceptar la posición oficial de la que estoy investido, mi programa fue de unión, de no servir a los intereses y miras de un estrecho círculo, sino a los intereses comunes y permanentes. Veo que no es estimado el sacrificio que he hecho, y antes al contrario, soy hostilizado por los mismos hombres que me debían de sostener, correspondiendo así a mi lealtad...". ${ }^{12}$ Un sector del mitrismo correntino que se había demostrado disconforme con su candidatura se hizo fuerte en la ciudad de Goya, desde las páginas del diario La Esperanza se proclamó principista ${ }^{13} \mathrm{y}$ criticó la espuria alianza del oficialismo con el "caudillaje de la campaña". Debió también soportar Lagraña la crítica del periódico capitalino El Independiente, vocero de los partidarios del caído gobierno de Rolón acérrimos opositores del mitrismo. En tercer lugar tuvo que enfrentar un conflicto internacional. El 13 de abril de 1865 la capital correntina fue ocupada por tropas paraguayas, el gobernador se vio obligado a retirarse instalándose en San Roque donde recibió la diligente ayuda del general Cáceres. La guerra cohesionó a los grupos mitristas y dio una breve oportunidad a quienes habían caído en desgracia tras los sucesos revolucionarios de diciembre de 1861. Sin embargo los reveses del Riachuelo y Yatay acabaron con las esperanzas de los invasores y sus adherentes correntinos. En octubre de 1865 el ejército paraguayo se replegaba hacia su país, en noviembre del mismo año Lagraña volvía a la capital, le restaba sólo un mes para finalizar su mandato. Su sucesor, Evaristo López ${ }^{14}$, fue electo cumpliendo la voluntad de Nicanor Cáceres convertido ahora en el hombre fuerte de la provincia. El mitrismo correntino y la guerra habían logrado encumbrar al "caudillaje de la campaña".

A excepción de esta última contrariedad, verdadero imponderable que motivó por razones de fuerza mayor relegar toda acción que no tuviera otro fin que la expulsión de los paraguayos, Lagraña dedicó sus dos primeros años de gestión a encaminar la provincia por la senda del crecimiento económico que debía convertirse en el nuevo motor de la

\footnotetext{
${ }^{10}$ Que como correspondía habían vuelto a pasar a la jurisdicción nacional, luego de resolverse la crisis provocada por la batalla de Pavón. Dicha transferencia se había realizado con anterioridad en el año 1855 a favor del gobierno central de Paraná, significando una disminución de los ingresos provinciales cercana al 50\%.( SCHALLER, 2002, p. 13)

${ }^{11}$ La percepción de este impuesto fue otorgada a las provincias por ley 30-11-1854, en compensación por la pérdida de las aduanas. Corrientes reglamentó su cobro por decreto del 11-02-1857. Debían pagarlo los propietarios de terrenos y capitales en giro superiores a $1.000 \$$ (el 30-03-1859 se redujo a $500 \$$ ) y consistía en el $4 \%$ del valor de los mismos. (SCHALLER, 1995, p. 45.)

${ }^{12}$ Carta de Manuel Ignacio Lagraña a José Pampín. 23-02-1863. A. G. P. C. FONDO MANTILLA. Archivo Pampín. Legajo 17. (1869-1872).

${ }^{13} \mathrm{Su}$ principismo como tantos otros se debía a que quedaron relegados del poder. Santiago Baibiene uno de sus integrantes demostraría que tenía buenos dotes para el pragmatismo a fines de la década de 1860 y principios de la siguiente. (CASTELLO, 1984, pp.431-442.)

${ }^{14}$ Era Jefe Político (jefe administrativo del departamento) de Goya en el año 1865.
} 
Alvarado. El gobernador Lagraña decidido obrero del mitrismo

historia correntina. ${ }^{15}$ Para ello hizo uso de todos los instrumentos que la precaria estructura institucional y política de la provincia ponía en sus manos.

\section{El catecismo de El Progreso}

La ciudad de Corrientes, que era el centro más poblado con cerca de diez mil habitantes ${ }^{16}$, no dejaba de ser una villa modesta con calles de arenas y casas sencillas. ${ }^{17}$ Las localidades del interior habían crecido, sin embargo predominaba la población rural que rondaba el 90\%. (SCHALLER, 1995, pp. 47-58). Estas características demográficas no facilitaban la actividad asociativa, ${ }^{18}$ los espacios públicos eran exiguos y las estrategias políticas se definían en domicilios particulares. No obstante durante el gobierno de Lagraña llegaron a editarse tres periódicos, dos en la capital y uno en la ciudad de Goya.

El oficialismo tenía como vocero a El Progreso, el mitrismo disidente se expresaba desde Goya con La Esperanza y los urquicistas lo hacían desde El Independiente. El precio de la suscripción y el alto porcentaje de analfabetos ${ }^{19}$ hacían que la "opinión pública" fuera un núcleo muy reducido de la sociedad correntina, la clase principal, ${ }^{20} \mathrm{de}$ tal manera los actores y las exclusiones políticas se mantenían prácticamente invariables a pesar de la amplificación de los debates. ${ }^{21}$

\footnotetext{
${ }^{15}$ Era la invención del progreso, definida por la escuela escocesa (D. Hume y A. Smith) en el siglo XVIII, que reducía la causa del cambio social a la economía y negaba legitimidad al enfrentamiento social y a la lucha política. Para acceder al peldaño superior de la humanidad (Gran Bretaña) había que seguir el programa del liberalismo económico que defendiendo la propiedad privada prometía un futuro de prosperidad para todos. Las transformaciones políticas serían corolario del desarrollo económico. (FONTANA, 2001, pp.107-127.)

${ }^{16}$ La población aproximada de la provincia era de 110.000 hab., la densidad era muy baja de 0,9 hab. por $\mathrm{km}^{2}$. El 70\% se concentraba en el noroeste provincial, luego le seguía el sur con un 19\% y las misiones con el $11 \%$. Eran estas últimas sin embargo las regiones que más habían crecido en los últimos años. (SCHALLER, 1995, pp. 47-58.)

17 "La ciudad de Corrientes se diferencia de otras ciudades Argentinas, en los corredores a la calle de sus casas, lo que da en ciertas horas un aspecto triste [...] La extensión de la ciudad de Norte a Sud es de trece cuadras, y menos de E. a O.” (QUESADA, 1857, pp. 39-40)

18 "Los espacios públicos para hacer política y difundir las ideas partidarias eran escasos, el limitado dinamismo social del lugar llevaba a ello [...] En Corrientes la actividad de difusión estaba dada por los ligámenes personalizados de quienes difundían las ideas, salvo en algunas oportunidades se las difundían en pulperías o tabernas [...] Debemos considerar también que los espacios de diálogos y construcción de la militancia política se daban en los domicilios particulares de algunos referentes locales, donde se conformaban reuniones para trabajar estrategias electorales o políticas.” (RAMÍREZ BRASCHI, 2004, pp. 36-37)

${ }^{19} \mathrm{De}$ los 110.000 hab. que aproximadamente tiene la provincia, sólo saben leer, también aproximadamente, el 16\%. REPÚBLICA ARGENTINA. PRIMER CENSO NACIONAL. Año 1869. Bs. As., el Porvenir, 1872. Y (SCHALLER, A. E. 1995)

${ }^{20}$ La clase principal constituía el 5\% de la población, el resto era pueblo llano pues Corrientes carecía prácticamente de sectores intermedios. Para realizar este cálculo aproximado, hemos tomado como referencia el número de contribuyentes que pagó la Contribución Directa en 1857: 923 lo multiplicamos por cinco y sacamos su porcentaje en relación a la población total según el censo del mismo año: 85.447.

21 "Oficialismo y oposición producirán entonces interpretaciones divergentes sobre el asunto de la genuina opinión pública, la que lejos de convertirse en un ideal de tribunal objetivo ante el cual se resuelven las posiciones contradictorias, se transforma en otro escenario más de los enfrentamientos políticos, marcado
} 
En los tres periódicos se pueden observar todos los recursos de la prensa facciosa de la época. El del lugar común, que le permitía ocultar las innovaciones bajo un tranquilo barniz de tradición, de esta manera surgían de la más cara herencia partidaria, haciendo presentar lo nuevo como viejo lo cual resultaba muy útil para defender una política en constante redefinición. La despreocupación por la verdad histórica era un obligado corolario porque los cambios constantes de la política obligaban a manipular el pasado para justificarla, en esto necesitaba contar con el olvido y la complicidad del público. Contraposición entre los seguidores de la luz y los secuaces de las tinieblas una combinación de monotonía de argumentos y recursos expresivos describían la crueldad de las políticas de los adversarios: solidaridad facciosa, ambición desorbitada, falta de escrúpulos, indiferencia frente al sufrimiento, ceguera frente al rumbo inexorable de la historia, etc. El periodista apóstol era quien señalaba desde su visión maniquea, cuál era el camino que conducía a la utopía del bien, que era, claro está, el de la facción a la cual pertenecía. (HALPERÍN DONGHI, 1985, pp. 144-168) De esta manera cada grupo definía su comunidad imaginada y al mismo tiempo la construía luchando por realizarla. Los editoriales, las columnas eran banderas que reunían e identificaban a los contendientes del espacio público. (PALTE, 2004, pp. 180-181)

El Progreso ${ }^{22}$, prensa oficiosa de Lagraña, aconsejaba a los correntinos desde sus editoriales a dejar atrás las luchas del pasado:

"Hablar de política y sobre política es remover las cenizas de nuestras guerras intestinas; activar las llagas gangrenosas que conservan en su cuerpo los partidos; es no comprender lo que nos conviene e interesa, es hacer arder de nuevo la tea de la discordia; es desear que se incendien nuestras verdes y floridas campiñas; es finalmente no querer que cunda por doquiera el progreso y la industria, sino levantar el pendón sangriento de las revueltas, del robo y de los asesinatos, para abrir de nuevo el templo de Jano. Estas reflexiones nos hacíamos con motivo de saber que algunas personas se ocupaban de censurar nuestro proceder, por haber cometido el pecado de no hablar en nuestros editoriales, con generalidad, sino de asuntos de industrias útiles y agrícolas, en vez de tratar políticas [...] Lo que es nosotros, no nos cansaremos de repetir, aunque les disguste a los politicones de nuevo cuño. Algodón, Algodón, Algodón. Industrias útiles. Cultura en nuestras masas. Paz. Progreso y Civilización." ${ }^{23}$

por las mismas exclusiones que la política electoral. Es decir, la misma brecha existente entre el ideal de gobierno representativo y las prácticas concretas de un proceso de deliberación racional orientada al interés público, y las prácticas concretas excluyentes a través de las cuales el oficialismo y la oposición se disputaban el terreno en el cual se formaba la opinión pública" (ZIMERMANN, 1998, p. 48)

${ }^{22}$ Salía jueves y domingos. Se editaron 202 números desde el 17 de mayo de 1863 hasta su clausura, tras la invasión paraguaya, el 13 de abril de 1865. (MANTILLA, 1887, pp. 54-55)

${ }^{23}$ El Progreso. 08-10-1863. Hemeroteca. A. G. P. C. 
Había que seguir el ejemplo de las naciones civilizadas del planeta, en donde la política era dinamizada por la economía que perfeccionaba las instituciones permitiendo a sus habitantes gozar de la libertad. ${ }^{24} \mathrm{La}$ tranquilidad que se abría en la república con la victoria de Mitre en Pavón lograría el ingreso de los capitales y trabajadores europeos que volverían productivos nuestros "desiertos". ${ }^{25}$ Corrientes no debía apartarse de esta senda que prometía "frutos sin cuento y un porvenir de esperanzas" 26

Ya hemos señalado más arriba la presencia de otros periódicos en la provincia que no compartían esta visión idílica de la prensa oficialista. Uno de ellos era La Esperanza ${ }^{27}$ expresión del mitrismo principista que desde Goya fustigaba la alianza del oficialismo con el caudillaje de la campaña obligando al gobierno a defenderse desde las páginas de El Progreso:

"No creemos que las doctrinas del colega de Goya sean el medio de encaminar al pueblo al conocimiento de sus derechos, ni menos a cimentar el bienestar que tanto necesitamos... Si hay caudillos como dice el colega, trabajemos entonces por el reinado de los principios, por la paz, que es el medio de anonadarlos. Si hay arbitrariedades, denunciemos sin pasión a la autoridad sin transigir con influencias ilegítimas. Si hay un error indiquémoslo para prevenirlo en adelante. Pero combatir con la acritud, con los epítetos y con la rabia de otros tiempos es no comprender la época en que se escribe... Un antagonismo irracional, es el triunfo de una política de reminiscencias funestas. Una oposición sistemada (sic.) es el preludio de la anarquía desoladora. Si hemos asistido fervorosos al progreso moral que la política de los pueblos Argentinos ha revelado, declarándose animosa de integridad y de fusión para no detener el movimiento progresivo, y dar la estabilidad de la paz a todas las empresas, debemos a todo trance adistar (sic.) lo que demore ese día deseado y ahogar en el pecho todo resentimiento ilegítimo. Lo contrario sería el rol de los demoledores que trabajan con el mismo tesón tanto en la paz como en la guerra.

\footnotetext{
24 “...Los Estados Unidos y la Inglaterra lo demuestran claramente; allí la política recibe su principal impulso del movimiento mercantil, y de las necesidades industriales y en ambos hemisferios ellos son considerados como modelos de instituciones constitucionales y como los guardianes de la libertad" El Progreso. 04-101863. Ibíd.

25 "Debemos confesarlo: el espíritu de las grandes empresas, no ha nacido para el corazón argentino: necesitamos que el extranjero venga a América a promoverlo, a sacudirlo, a hacerlo nacer, si así puede decirse...” El Progreso. 13-03-1864. Ibíd.

26 "Las masas del pueblo, más que nunca, ahora se encuentran ocupadas en trabajos agrícolas e industriales, que les produce frutos sin cuento y un porvenir de esperanzas basado en la paz de la provincia..." El Progreso 05-11-1863. Ibíd.

${ }^{27}$ Se editó en Goya entre 1862 y 1865, la caída de dicha localidad en manos paraguayas interrumpió su salida. Vuelve a publicarse en 1866 pero desde la capital provincial hasta su cierre definitivo en 1874. (MÉNDEZ PAZ, 1953, pp. 33-34)
} 
Acepte el colega nuestro consejo y no se proponga recoger tan triste celebridad"28

El tono del alegato permite ver más allá de las diferencias ${ }^{29}$, la comunión de intereses que buscaba alentar el "movimiento progresivo" que reinaba en la república. Esta perspectiva común se evidenciaría tras la ocupación paraguaya que motivó el cierre de El Progreso y transformó a La Esperanza en el vocero del gobierno de Lagraña hasta la caída de Goya en manos del general paraguayo Wenceslao Robles en mayo de 1865. Con El Independiente $e^{30}$ las diferencias eran irreconciliables. Expresión de los partidarios del caído gobierno de Rolón sus editoriales combatían tanto al gobierno provincial como al nacional. A poco de salir este diario opositor, la prensa oficialista alertaba a la opinión pública:

"El Independiente que ha visto la luz en estos días fiel a los instintos perversos de sus partidarios, ha mostrado desde su primer número que ese partido no cambia, que cuando esgrime la pluma del periodista solo produce el insulto y la calumnia [...] El partido liberal demasiado fuerte por la santidad de sus principios, no puede conmoverse por los simples graznidos de esos fatídicos búhos, que en otro tiempo eran precursores de días luctuosos para los argentinos." 31

La guerra de la triple alianza iba a poner en aprietos la "fuerza de la santidad liberal" por unos pocos meses, para luego reforzarla y encaminarla por la senda correcta siguiendo al presidente Mitre que enseñaba "la religión política liberal"32. El Progreso, mientras salió, predicó su catecismo en la provincia de Corrientes.

\section{La instrucción pública}

La educación de las masas era un instrumento de mayor alcance para divulgar la doctrina liberal, pero de plazos más largos para ver los resultados. La revolución de fines

${ }^{28}$ El Progreso. 28-04-1864. Hemeroteca. A. G. P. C.

${ }^{29}$ De hecho el diario La Esperanza había nacido para ayudar al gobierno de José Pampín y defender la causa de Pavón en Corrientes. Así se lo hacía saber, antes de adquirir la imprenta, Julio Solano al gobernador Pampín: “...Voy pues a fundar un periódico en esta ciudad, que como le dije cuando tuve el gusto de estar con U.; hace mucha falta aquí. Yo creo contar con la cooperación de U.; pues U. bien sabe que el periódico no puede ser amigo de otro que de U.; sea suficiente el servicio del fundador y dueño de él, adicto decidido de su amistad y de su gobierno que tiene suficiente simpatías en este Pueblo y en toda la provincia." Goya, julio de 1862. A. G. P. C. FONDO MANTILLA. Archivo Pampín. Legajo 47. 1861-1862.

${ }^{30}$ Se publicó entre abril de 1864 y octubre de 1865 . La ocupación paraguaya divide su edición en dos etapas, durante la primera (abril/1864-abril/1865) fueron sus editores Federico Z. Boetti y Víctor Silvero y tuvo como redactores a José Benjamín Romero y el antes mencionado Boetti. En la segunda (abril-octubre 1865) tuvo como redactores al coronel paraguayo Coroliano Marquéz, a un ayudante de apellido Carreras y a Federico Z. Boetti. (MÉNDEZ PAZ, 1953, P. 35)

${ }^{31}$ El Progreso 10-04-1864. Hemeroteca. A. G. P. C.

32 "El Presidente Mitre, enseña la religión político-liberal. Los comicios públicos, la discuten y las prensas ilustradas de la Nación, imprimen los resultados de sus deliberaciones.” El Progreso. 05-11-1863. Ibíd. 
de 1861 había repercutido negativamente en esta área, que se vio notablemente afectada. ${ }^{33}$ La administración provincial dedicó sus mejores esfuerzos a revertir este cuadro sombrío ${ }^{34}$

En junio de 1863 se restablecía el Colegio Argentino bajo la dirección de Antonio Zinny. ${ }^{35}$ El diario oficialista celebraba la designación del director cuya principal virtud era ser "completamente ajeno a la política" y confiaba en que su emulación por parte de los jóvenes produciría "caballeritos instruidos". ${ }^{36}$ La restablecida institución abarcaba los niveles primario y superior preparatorio recibiendo en ambos a becados de toda la provincia que debían cumplir dos condiciones: aplicación al estudio y pobreza. El gobierno confiaba que en el Colegio se "formaría el núcleo de la democracia" ${ }^{37}$ correntina. Había en esto plena coincidencia con la política educativa nacional que consideraba fundamental la educación de las elites para combatir la barbarie y por ello daba preponderancia a los niveles secundario y universitario. (GIBELLI, 1968, T. IV, pp. XLVI-XLVIII) Al solicitar los nombres de los tres becados correntinos al Colegio Nacional de Buenos Aires ${ }^{38}$ el Ministro Costa señalaba al gobernador que dicho establecimiento no sólo contribuiría a "formar ciudadanos útiles para la patria, por su inteligencia y su saber..." Sino que también estrecharía los vínculos que debían "cimentar la unión en que por fortuna" se encontraba "la familia Argentina" ${ }^{39}$ Había otros integrantes de la familia correntina, que si bien no llegarían a ser caballeritos instruidos, preocupaban a la administración provincial.

Durante el gobierno de Lagraña 36 escuelas primarias albergaban en toda la provincia, aproximadamente, a 3.000 alumnos $^{40}$, vale decir que concurrían a la escuela

${ }^{33}$ En 1863 el Ministro de Justicia, Culto e Instrucción Pública de la Nación, Eduardo Costa, ordenó un relevamiento del estado de la educación del país; los informes fueron desalentadores. (PUIGGRÓS, 2003, P. 78)

${ }^{34}$ Sin embargo, según el informe de Ramón Contreras y Cecilio Echeverría de 1871, en 1865 era “... evidente pues que la Provincia de Corrientes tenía más generalizada la instrucción primaria con relación a su población en más de tres veces, que la Provincia de Buenos Aires en los mismos términos." INFORME A CERCA DE LA PROVINCIA DE CORRIENTES PRESENTADO A LA COMISIÓN DE LAEXPOSICIÓN NACIONAL DE CÓRDOBA, POR CECILIO ECHEVERRÍA Y RAMÓN CONTRERAS. En Boletín Oficial de la Exposición Nacional de Córdoba en 1871. Vol. 6º Serie de Memorias No 2. Bs. As., Imprenta, litografía, fundición de tipos a vapor de la Sociedad Anónima 126-Belgrano-126, 1873. P. 3.

${ }^{35}$ Registro Oficial Provincia de Corrientes. (En adelante R. O. P. C.). Año 1863. Decreto 19-06.1863.

${ }^{36}$ El Progreso 05-07-1863. Hemeroteca. A. G. P. C.

37 “... Un Colegio como este donde se enseñan las lenguas vivas, filosofía, ciencias exactas y música, no puede nadie negar su importancia. Por nuestra parte apreciadores como el que más del adelanto de la juventud deseamos que cada día se avance más en este camino, que tan solo así formaremos el núcleo de la democracia" El Progreso. 21-04-1864. Hemeroteca. A. G. P. C.

${ }^{38}$ Creado el 14 de marzo de 1863 bajo la presidencia de Mitre y la gestión educativa de su ministro Costa. Fueron nombrados como Rector el Dr. Eusebio Agüero y Director de Estudios el pedagogo francés Amadeo Jacques. Acogían cuarenta becados del interior y cien de Bs. As. También se admitían externos por cuenta de sus padres. (ROSA, 1979, P.57.)

${ }^{39}$ Correspondencia Oficial. A. G. P. C. t. 186. F. 13. Bs. As. 02-04-1863. Eduardo Costa, Ministro de Justicia, Culto e Instrucción Pública de la Nación a Manuel Ignacio Lagraña.

${ }^{40}$ Según El Progreso para 1864 había un total de 43 escuelas primarias de varones con 2.044 alumnos y 27 escuelas primarias de mujeres con 1.058 alumnas. El Progreso 13-11-1864. Hemeroteca. A. G. P. C. Este dato difiere del que da Castello en su obra, no en el número de escolarizados pero si en el número de establecimientos. Según este autor existían 36 escuelas en total. Es una pena que no indique la fuente, 
alrededor de un $10 \%$ de los niños en edad de hacerlo. ${ }^{41}$ La constitución provincial, reformada en $1864^{42}$, establecía en su artículo $23^{\circ}$ que era: “...obligación del Gobierno facilitar a todos los habitantes de la Provincia la adquisición de la instrucción primaria, debiendo a este objeto establecer en cada pueblo de ella al menos una escuela para varones y otra para niñas" ${ }^{\$ 3}$ Tal norma distaba mucho de la realidad, la mayoría de los pueblos no contaba con un edificio siquiera para escuela y debían alquilar una casa para tal fin, siendo no pocas veces la del preceptor la que cumplía esta función. Cuando el inmueble existía estaba con frecuencia en muy malas condiciones y no reunía los elementos y útiles necesarios para el dictado de clases. A mediados de 1863 la Comisión Inspectora de Escuelas Públicas de Mburucuyá reflejaba esta situación: “... Ninguna escuela existe en todo el departamento, por consiguiente, no hay método de enseñanza, ni libros que sirvan de textos, ni Preceptor. El edificio que servía de escuela en este Pueblo no existe más del que algunos palos parados, no hay ninguna clase de útiles, en una palabra hay que hacer de nuevo todo, desde el edificio, mesas, asientos..." ${ }^{44}$

En 1863 un subsidio nacional específico para estos menesteres vino a auxiliar al alicaído erario provincial ${ }^{45}$, sin embargo la necesidad era tanta que la ayuda resultó escasa. Para solucionar este problema se apeló a la tradición de las suscripciones ${ }^{46}$, muy frecuentes en estas épocas de grandes carencias y pocos recursos. El éxito de esta medida dependía de la confianza que tenían los vecinos en sus autoridades y de los bolsillos de los contribuyentes. Así el emprendedor juez de paz de Empedrado podía escribir lleno de júbilo al ministro de gobierno: "Es digna de elogio la marcha de las Comisiones que para atender cada Escuela se han formado... No es menos meritoria la de los demás vecinos en general, pues cada uno contribuye voluntariamente con un tanto según sus posibles mensualmente..." ${ }^{47} \mathrm{Y}$ desde Lomas otro funcionario comentar en tono pesimista la imposibilidad de levantar una suscripción "por cuanto los individuos del Departamento en su generalidad son pobres y sólo se encuentran con algunos recursos cuando la producción

porque sus números se condicen mejor con los datos que ofrecen los jueces de paz en la correspondencia oficial. (CASTELLO, 1985, P. 408.)

${ }^{41}$ Según el censo de 1869 se registraron en Corrientes 32.937 niños de 6 a 14 años. PRIMER CENSO NACIONAL. Op. Cit. T. 2. P. 218.

${ }^{42}$ El 25 de mayo de 1864 fue sancionada la reforma de la Constitución Provincial, esto permitió entre otras cosas hacer más directa la elección del gobernador y creo la figura del vicegobernador para reemplazarlo en caso de eventualidades bien consignadas; se ampliaron las declaraciones de derechos y garantías, explicitándose las referentes a la inviolabilidad de la propiedad, a la seguridad personal, y a la libertad electoral. R. O. P. C. Año 1864. Pp. 132-148.

${ }^{43}$ Ibíd. P. 135.

${ }^{44}$ Correspondencia Oficial. A. G. P. C. t. 187. F. 127. Mburucuyá. 17-06-1863. Comisión Inspectora de Escuelas Públicas: Juan Soto, Félix Vallejos, Fray José Lamorta al Ministro de Gobierno Juan José Camelino.

${ }^{45}$ Luego de los desalentadores informes entregados al Ministro Costa, este decidió subsidiar a las provincias en sus presupuestos educativos. Debemos tener en cuenta que la instrucción primaria era (y es, art. $5^{\circ}$ ) competencia de las finanzas provinciales según la constitución nacional. (PUIGGRÓS, 2003, P. 78.)

${ }^{46}$ Colecta entre vecinos de posibles autorizada por el gobierno para solventar cualquier necesidad de la población: juzgados, pisos de carretas, templos, escuelas, etc.

${ }^{47}$ Correspondencia Oficial. A. G. P. C. t 186. F. 72 Empedrado 16-04-1863. José A. Pombo, juez de paz, al oficial mayor de gobierno Gonzalo Figueroa. 
agrícola empieza a producir, por consiguiente su realización [de la suscripción] es muy difícil e irrealizable" ${ }^{\prime 48}$ El problema edilicio y la carencia de mobiliario y útiles no era el único a resolver. Cubrir las vacantes de preceptores era todo un inconveniente “... por no haber personas idóneas quienes quieran encargarse de cuyos empleos en este Departamento, pues algunas personas inteligentes que hay, no han querido dedicarse en ese ejercicio" ${ }^{49}$. Esta queja provenía de San Miguel, la misma pesadumbre manifestaba el juez de paz de Itatí que reconocía no poder cambiar al inepto que tenía al frente de la escuela de varones por no tener a nadie que quisiera reemplazarlo ${ }^{50} \mathrm{y}$ en la localidad de San Martín se había nombrado al frente de la escuela de niñas a una preceptora que no sabía escribir.$^{51}$ Lagraña y El Progreso estaban convencidos que "instruir a las masas del pueblo" era "una misión santa y augusta de los verdaderos Gobiernos liberales" realidad era terca y no quería aprender esta lección tan sencilla.

\section{Los juzgados de paz}

El catecismo liberal de El Progreso y la prédica de la enseñanza pública con maestros "ajenos a la política" transcurría, prácticamente, sin sobresaltos. Sin embargo, las lecciones de los preceptores darían resultado a largo plazo y los editoriales debían plasmarse en la realidad, dejar de ser pregón y concretarse. Para realizar esta tarea el gobierno contaba con los jueces de paz ${ }^{53}$ que a lo largo y ancho de la provincia debían hacer efectivas las promesas del mitrismo correntino.

${ }^{48}$ Correspondencia Oficial. A. G. P. C. t. 197. F. 188. Lomas 28-04-1864. José Navarro, juez de paz, al Ministro de Gobierno Juan José Camelino

${ }^{49}$ Correspondencia Oficial. A. G. P. C. t. 187. F. 115. San Miguel 07-06-1863. Romualdo Canteros, juez de paz, al Ministro Juan José Camelino.

${ }^{50}$ Correspondencia Oficial. A. G. P. C. t. 188. F. 4. Itatí 11-07-1863. Evaristo Bedoya, juez de paz, al Ministro Juan José Camelino

51 "Preguntada sobre este punto: la Preceptora contestó que no sabía escribir; y que al aceptar ese empleo había hecho presente al Sr. Juez de Paz, de este inconveniente; y que sin embargo no había sido un obstáculo." Correspondencia Oficial. A. G. P. C. t. 206. F. 71-72. San Martín 14-02-1865. Comisión Inspectora de Escuelas: Pedro Dejeane, Pablo Ruíz Díaz, Tiburcio Acuña, José Gonçálvez Ferreira y Víctor Richard al Ministro Juan José Camelino.

${ }_{52}^{52}$ El Progreso. 02-08-1863. Hemeroteca. A. G. P. C.

${ }^{53}$ La provincia se dividía en departamentos, durante la gobernación de Lagraña, con la creación del departamento de Lavalle, su número llegó a veintidós. Desde la organización institucional del país, gracias a la cual las fuerzas militares pasaron a depender del estado nacional, y hasta la instalación de las municipalidades a principios de 1864, la máxima autoridad administrativa de los departamentos fueron los jueces de paz, cuya designación correspondía al ejecutivo provincial (con la excepción de la Capital y Goya donde sólo tenían tareas judiciales pues las administrativas estaban a cargo del jefe de policía y el jefe político respectivamente). Dentro de sus múltiples funciones estaban: recaudar impuestos, vigilar el orden, administrar el correo, atender el juzgado y procurar el adelanto del departamento a través de las obras públicas. Sumado a ello con frecuencia integraban las diferentes comisiones (Reguladora de la Contribución Directa, Inspectora de Escuelas, Junta Clasificadora de Inscripción al Registro Cívico), que se formaban en sus distritos. Para esto contaban en el mejor de los casos con la colaboración de un ayudante y un escribiente para las tareas administrativas y para las policiales con un comisario y tres celadores. (SCHALLER, 1998, pp. 41-62) 
La empresa no era nada fácil, en la mayoría de los pueblos estaba todo por hacerse. Tal era el caso de Mburucuyá, que estaba lejos de ser una excepción,

"Los edificios públicos" informaba el juez de paz "en su estado de completa ruina demandan imperiosamente del Excelentísimo su preferente atención. El abandono completo con que ha sido mirada esta fracción de la Provincia de Corrientes, por las autoridades anteriores, han sido causa para que el edificio de la Escuela permanezca sobre una sola pared, y el del mercado en cuatro desunidos horcones que el eco de la tradición nos enseña haber existido para tan necesario fin" 54

El exiguo presupuesto obligaba a las autoridades a utilizar el ingenio ${ }^{55}$ pues los vecinos eran remisos a participar en suscripciones que no tuvieran otro fin que el de escuelas y templos. Cuando el ingenio no era suficiente y las necesidades urgentes y elementales, apelaban al peculio personal, Victorio Quiroz, juez pedáneo ${ }^{56}$ de la $4^{\mathrm{a}}$ sección de Restauración (Paso de los Libres) ${ }^{57}$ reclamaba al ejecutivo provincial: "ruego a U. observe a S. E. que continuamente se me originan gastos como el comprar papel, tinta, y obleas que todo lo compro con mi propio dinero. Si mis circunstancias no fuesen tan limitadas no trepidaría en hacer estos pequeños gastos. En vista de las razones que llevo expuestas, desearía que S. E. el Sr. Gobernador hiciera asignar una pequeña cantidad para gastos de oficina." ${ }^{58} \mathrm{El}$ gobierno provincial ofrecía la paradoja de alentar el adelanto material siendo austero, llegando a recortar el personal de los juzgados de paz. Por supuesto los jueces elevaron su queja pues sus subalternos eran sumamente necesarios para "el desempeño de tantas atenciones" ${ }^{\prime 59}$ que requerían sus respectivos departamentos.

Como podemos colegir, los jueces de paz, podían decir en sus departamentos "el estado soy yo" no por arbitrarios, que muchos lo eran, sino por la total carencia en

${ }^{54}$ Correspondencia Oficial. A. G. P. C. t. 186. F. 4-5. Mburucuyá 31-03-1863 Francisco Aguirre, juez de paz, al oficial mayor de gobierno Gonzalo Figueroa.

55 “...gastos en peones no ha habido porque este juzgado ha empleado para el efecto a todos aquellos que incurrían en faltas graves y otras ocasiones pagando de las multas que se imponían por faltas policiales y otros con que se ha hecho ahorro de consideración...” Correspondencia Oficial. A. G. P. C.C. O. P. C. t. 190. F. 43. Empedrado 17-09-1863. José A. Pombo, juez de paz, al Ministro Juan José Camelino.

${ }^{56}$ Estaban al frente de los distritos departamentales (subdivisiones del departamento) se ocupaban de juicios de hasta $25 \$$ fuertes y en los de injurias leves en que podían imponer multas y arrestos hasta 10 días. (GÓMEZ, 1922, Pp. 364.)

${ }^{57}$ El dos de marzo de 1864, vale decir durante el mandato de Lagraña, una ley derogó el decreto del 27-011848 restituyendo el nombre de Paso de los Libres a dicha localidad. R. O. P. C. Año. 1864. pp. 59-60.

${ }^{58}$ Correspondencia Oficial. A. G. P. C. t. 186. F. 110. Restauración 28-04-1863. Victorio Quiroz, juez pedáneo $4^{\mathrm{a}}$ sección, al oficial mayor de gobierno Gonzalo Figueroa.

59 "Contestando a su nota 24 del presente en el que S. S. me dice que el Superior Gobierno ha dispuesto, se anexase el cargo de Escribiente al de Ayudante, con el sueldo de veinte pesos mensuales: haré notar a S. S. para que lo eleve al conocimiento del Superior Gobierno; que este juzgado Cabeza de Departamento de una numerosa población, en el que incesantemente los asuntos se suceden y se agolpan por falta de tiempo para despacharlos no es suficiente con un solo individuo para el desempeño de esos dos cargos." Correspondencia Oficial. A. G. P. C. t. 185. F. 248. Caá Catí 31-03-1863. Santos Insaurralde, juez de paz, al Ministro de Gobierno. 
que desempeñaban sus funciones. ${ }^{60}$ Considerando la importancia de estos funcionarios El Progreso se permitía aconsejar a Lagraña: “...trate de buscar hombres que en toda la extensión de la palabra sean dignos de ocupar estos puestos [jueces de paz], para que contribuyendo al mayor adelanto del país, den impulso a los pueblos de la jurisdicción haciendo marcar el amor al trabajo: única fuente de riqueza de las sociedades bien organizadas, que propenden a su engrandecimiento y ventura..." ${ }^{61} \mathrm{Al}$ frente de las distintas localidades hubo jueces probos, diligentes, emprendedores como José A. Pombo en Empedrado cuyo ejemplo era resaltado por la prensa oficialista ${ }^{62}$, hubo otros que con esfuerzo sobrellevaban la pesada carga "... a vuestra excelencia le consta que soy poco versado para llevar la pluma con la lucidez y precisión que se requiere para el buen desempeño como funcionario público." ${ }^{93}$ Hubo también algunos duramente criticados por no corresponder con su conducta a "los nuevos tiempos" que vivía la provincia, como el juez de paz de Esquina, acusado de tener "antecedentes muy manchados", no saber leer pero si firmar y dejarse rodear por un "comité o comparsa" de conducta "inmoral y funesta" que cometió "desafueros sin cuento". ${ }^{64}$ No importaba las condiciones que tuvieran a todos les esperaba una ingente tarea, Juan Cirilo Leiba lo remarcaba en una carta a Lagraña:

"S. E. ha tenido el honor de honrarme con el cargo de Juez de Paz y demás empleos que tiene esta admiración a su cargo que son los siguientes: Juez de Paz, Administrador de Correo, Juez de Comercio, Presidente de la Contribución directa, Presidente de las Escuelas Públicas, Presidente de la Comisión de Tierras, de Terrenos y Chacras, Juez de Pobres y Menores, Escribano Público, Jefe de Policía y Receptor de Alcábalas. S. E. no dejará

\footnotetext{
60 "El estado provincial estaba en franca formación y los entes gubernamentales no poseían efectivo dominio material sobre la cosa pública. Lo que hoy entendemos como "aparato" del Estado no se interpretaba en aquella época de la misma manera, sino que se asociaba al estado como relación de mando obediencia. Resumiendo los espacios efectivos de dominio del Estado provincial eran mínimos, casi inexistentes..." (RAMÍREZ BRASCHI, 2005)

${ }^{61}$ El Progreso 15-11-1863. Hemeroteca. A. G. P. C.

62 “... y deseamos tenga imitadores el Sr. Juez de Paz [Pombo] del Departamento "modelo" de Empedrado." El Progreso 02-08-1863. Hemeroteca. A. G. P. C.

${ }^{63}$ Correspondencia Oficial. A. G. P. C. t. 184. F. 240. Santo Tomé 27-02-1863. Tomás Araujo, juez de paz, a Manuel Ignacio Lagraña.

64 "El Juez de Paz que en este año hemos tenido, pertenece por su nacimiento a la plebe y sus antecedentes son muy manchados, así es que sorprendió a esta población la elevación de un hombre que solamente era digno del título de carnicero, su profesión hasta hoy poco es ladrillero, y ha dado pues un resultado como debía esperarse que correspondiese en su marcha a la calidad del juez. Este por su exceso de nulidad porque es de aquellos que no saben leer, pero saben firmar, luego fue rodeado de aquellos que saben explotar los puestos públicos dando por resultado haberse erigido varios en jueces que mandaban con la legitimidad del legítimo juez y cometían y cometen desafueros sin cuento, escudados en el nombre de este y son Florentino Loza, José Guastavino, Daniel Hayes y el Ayudante de Plaza. El origen de todos estos es muy oscuro y denigrado. Esta población está dividida en bandos desde que se observó la conducta inmoral y funesta observada por este comité o comparsa como son clasificados acá." Correspondencia Oficial. A. G. P. C. t. 203. F. 118-119. Esquina Telesforo Amadeo Díaz a Manuel Ignacio Lagraña
} 
de comprender, como es posible, el que un hombre sólo pueda desempeñar tantos empleos a la vez"65

Para terminar con esta situación e involucrar a los vecinos en la tarea del progreso provincial, los liberales correntinos confiaban en los beneficios de una nueva institución: el municipio.

\section{Los municipios}

Con el antecedente de los intentos de Pujol, (GÓMEZ, 1922, pp. 392-396) la legislatura provincial sancionó dos leyes en agosto de $1863^{66}$, que establecían el régimen municipal en la Capital y en los pueblos de los departamentos respectivamente. ${ }^{67} \mathrm{El}$ gobierno buscaba "crear el espíritu municipal, haciendo tomar parte a los vecinos en la ejecución de toda medida de pública conveniencia" ${ }^{68}$ Los municipios se constituirían en los ámbitos más apropiados para lograr el establecimiento de las libertades cívicas y políticas, convirtiéndose en verdaderas escuelas de ciudadanía (BONAUDO Y ZONZOGNI, 1999). Siguiendo con la metáfora, demás está decir que faltaba mucho para que hubiera egresados, no obstante era este un ámbito en el que era más factible el disenso. ${ }^{69}$

Los informes muestran un cuadro variopinto así desde Restauración el presidente municipal relataba entusiasmado al Ministro de Gobierno:

"La municipalidad se halló aquí al frente de innumerables dificultades; todo estaba por crearse; y efectivamente aquí no existía edificio para Escuela, aquí no había cementerio público, siendo el existente más bien un corral, aquí las calles eran completamente intransitables, la iglesia levantada a costa de tantos trabajos estaba otra vez por desmoronarse por no estar concluida, en fin aquí nada absolutamente nada se había hecho durante las pasadas administraciones, para hacer participar a esta villa de los adelantos, que exige el siglo en que vivimos. [...] Los ojos de los habitantes del Departamento estaban fijos

${ }^{65}$ Correspondencia Oficial. A. G. P. C. t. 207. f. 215. La Cruz 24-03-1865. Juan Cirilo Leiba, juez de paz, a Manuel Ignacio Lagraña.

${ }^{66}$ R. O. P. C. Año 1863. pp. 83-91.

${ }^{67}$ En nueve de los veintidós departamentos se instaló el régimen municipal a principios de 1864, en la Capital el 31 de enero y en Goya, Caá Catí, Bella Vista, Esquina, Saladas, Mercedes, Empedrado y Restauración (Paso de los Libres) el 7 de febrero. El municipio capitalino estaba compuesto por nueve miembros titulares y tres suplentes, los departamentales estaban formados por un consejo integrado por el juez de paz, cuatro vecinos titulares y dos suplentes. El mecanismo de elección era el mismo que regía para los diputados y se renovaban por mitades cada año. Sus funciones contemplaban: la seguridad, la higiene, la educación, las obras públicas y el gobierno autónomo de su tesoro. (GÓMEZ, 1922, pp. 396-397)

${ }^{68}$ Mensaje del Gobernador de la Provincia a la legislatura al abrir el período de sesiones ordinarias de 1864. R. O. P. C. Año 1863. P. 123.

${ }^{69}$ En la correspondencia oficial de los años del gobierno de Lagraña no se encuentran prácticamente reclamos por arbitrariedades en las elecciones a diputados, si aparecen, aunque pocos, en las elecciones a concejales. 
en ella, y el abajo firmado tiene el orgullo de decir que si no se han satisfecho todas las exigencias, por lo menos se han allanado las más importantes, y que la municipalidad ha merecido la aprobación de los hombres sensatos del pueblo..."70

Los vecinos de Curuzú Cuatiá anhelaban la instalación de tan benéfica institución y reclamaban al gobernador

\begin{abstract}
"Los exponentes, Señor no considerando a esta villa de peor condición que a sus pueblos hermanos; viendo por otra parte las ventajas que reportan a los pueblos desde que han principiado a funcionar en los puntos establecidos, las mejoras y adelantos de que participan; teniendo esta localidad muchas necesidades que llenar para el bien general, como son las escuelas de enseñanza pública tanto de varones como de niñas que no cuentan con edificio aparente, la construcción de un templo para predicar el evangelio y la moral cristiana, la compostura de las calles, y de otras necesidades que omitimos decirlas, y contando este pueblo con los recursos suficientes para ello desde que se le asignen las entradas de derechos que le pertenecen. Los exponentes suplican se sirva V. E. ordenar se conceda a este Pueblo lo que de justicia merece..."
\end{abstract}

En la comunidad de Bella Vista parecía reinar la indiferencia. “...Sin embargo conozco que es inoficioso" informaba el juez de paz "el trabajo de las elecciones[para concejales], pues tal vez ninguno de los electos admitan y así sucesivamente todos los ciudadanos se excusan a prestar servicio pues algunos han fijado carteles en las esquinas manifestando su negativa; así que las renuncias han de ser continuadas pero sin causa que les prive el servir sino la falta de voluntad..."72. La institución que debía catalizar el progreso de las comarcas, más allá de los resultados, produjo entusiasmo en algunos y en otros desdén o indiferencia. Pero tanto entusiastas como indiferentes pertenecían a un mismo sector social, la clase principal. Ellos eran los verdaderos convidados a participar en esta novel institución de la "república posible" (BONAUDO Y ZONZOGNI, 1999). Sin embargo su accionar debía llegar a todos, el adelanto material era una promesa universal. Futuro que la inmensa mayoría de la población esperaba sin ansiedad.

\footnotetext{
${ }^{70}$ Correspondencia Oficial. A. G. P. C. t. 199. F. 197-198. Paso de los Libres 02-07-1864. Abelardo Torres, presidente del consejo municipal, al Ministro de Gobierno Antonino Segovia.

${ }^{71}$ Correspondencia Oficial. A. G. P. C. t. 200. F. 59. Curuzú Cuatiá 07-1864. Vecinos: José Vicente Gómez, Vicente Ramírez, Julio A. Cabrera, Nicanor Cáceres, Ramón Regúnaga, Hipólito Acuña, W Reina y otros a Manuel Ignacio Lagraña.

${ }^{72}$ Correspondencia Oficial. A. G. P. C. t. 192. F. 142. Bella Vista 02-12-1863. Bernardino Fernández, juez de paz, al Ministro de Gobierno Juan José Camelino.
} 


\title{
El soberano
}

Como ya se señaló, Corrientes tenía aproximadamente un 90\% de población rural, casi su totalidad ocupaban tierras sin ningún título de propiedad, era la clase menesterosa que sobrevivía a base de una economía de subsistencia

\begin{abstract}
"El cultivo doméstico de maíz, batata, mandioca, zapallos, cítricos y otros vegetales, junto con la leche de algunos vacunos, la pesca en el amplio sistema hidrográfico provincial y la abundante caza de diversas especies de aves y mamíferos, contribuía a resolver, en distinto grado, el problema de la alimentación en buena parte de la población rural. Los ovinos, abundantes en la provincia, proporcionaban la lana que, como el algodón, se utilizaba ampliamente en la producción doméstica textil. A estos recursos se sumaba la fácil provisión de cuero..." (CHIARAMONTE, 1991, p. 65)
\end{abstract}

Sobre esta población rural que subsistía sin mayores inconvenientes se debía derramar la cornucopia del liberalismo.

A principio de la década de 1860 un $52 \%$ de las tierras de la provincia estaban en manos de propietarios particulares, la mayoría de ellas se encontraban en el noreste y sur provincial; las tierras fiscales se situaban en el centro, aledañas a los esteros del Iberá, y al este en las Misiones. (SCHALLER, 1995, pp. 131-132) Un reducido número de propietarios concentraba en sus manos grandes extensiones de tierra ${ }^{73}$ dedicadas a la ganadería, actividad que llevaban adelante sin mayores cuidados, ${ }^{74}$ a cargo de muy pocos peones. Trabajos estacionales aumentaban el personal temporario. De tal manera el grueso de la inversión recaía en la compra de la estancia y del ganado para poblarla. ${ }^{75}$

A pesar de la escasa mano de obra que requería este modelo productivo de ganadería extensiva, no era tarea fácil conseguirla. Pues como se dijo más arriba la mayoría de la población subsistía sin mayores problemas. Esta "vida salvaje y errante"76 dificultaba el

${ }^{73}$ Echeverría y Contreras señalaban en su informe, tomando como fuente el catastro realizado por José Caba-
llero entre 1857 y 1859 : "Los resultados que informa este catastro, hacen ver $1^{\circ}$ que el número de propie-
dades particulares rurales entregadas en su mayor parte al pastoreo, apenas alcanza en toda la provincia a
1245 leguas cuadradas y más de 65447 varas cuadradas; $2^{\circ}$ - que toda esa extensión de tierras se halla en
manos de un diminuto número de propietarios que en suma, apenas representa el número de 895 personas;
y $3^{\circ}$ - como consecuencia, que la tierra se encuentra organizada bajo la grande propiedad y dista mucho
de la época en que pueda ser entregada al cultivo para que entonces la propiedad se divida y subdivida
activamente para que sea más productiva y contribuya a la riqueza y al aumento de la prosperidad general"
INFORME... Op. Cit. P. 54 .
74 "Uno de los ramos fuertes de la producción es el pastoreo. Las haciendas vacunas, caballar, yeguarizo y
mular prosperan notablemente con un cuidado más o menos insignificante en toda la Provincia. El aumento
regular de su procreo, siempre da halagüeños resultados". Ibíd. P.63.
${ }^{75}$ En el año 1863 en Yaguareté Cora, José María Roxas y Patrón fundó una estancia con un costo total de
$\$ 64.054 ;$ el $40 \%$ correspondía a la compra de la tierra, el 57,6\% al ganado y el $2.4 \%$ restante a útiles y
herramientas. A. G. P. C. Tribunales. Civil Capital. (SCHALLER, 1995, p. 222.)
${ }^{76}$ Así describía Vicente Quesada la vida de los argentinos en su libro "La Provincia de Corrientes": "Los 
sometimiento a la disciplina del trabajo. Persiguiendo este fin la clase dirigente y principal recurrió a varios métodos.

En diciembre de 1863, Lagraña, dictó un decreto sobre conchavo de peones, dicha medida ponía en vigencia otra anterior, de noviembre de 1825. La norma, que como podemos ver no era nueva, obligaba a todos aquellos que no ejercían ningún oficio a conseguir un trabajo estable, de no hacerlo serían reputados vagos recibiendo los castigos correspondientes. ${ }^{77}$ Ramón Sangrá vecino de Bella Vista, exhortaba al gobierno desde las páginas de El Progreso:

"Este delito [vagancia], germen de la disolución y revoluciones, ha echado profundas raíces en este infortunado suelo en donde pululan los vicios y crece y se aumenta cada día la miseria y la disolución entre la clase que más debería contribuir al desarrollo de las artes y de la agricultura. De ahí que ni la previsión del legislador, será jamás suficiente si falta la vigilancia de las autoridades para impedir un mal que está en razón directa con el desenfreno de las costumbres y de las miserias de las clases proletarias, víctimas en muchas partes del abandono, de la infelicidad y de la abyección... Es un error creer que pueden impedirse los delitos con la sola publicación de leyes severas, sin cuidarse de la completa ejecución de las mismas, y por sólo este medio se puede mejorar las inclinaciones y condición de aquellos que prefieren sufrir las consecuencias de la miseria más espantosa antes que militar bajo la bandera honrosa y lucrativa del trabajo." 78

Cuidar la completa ejecución de las leyes era una tarea complicada para las autoridades desprovistas de medios, Sangrá lo sabía muy bien pues su localidad era un buen ejemplo, donde "gente desordenada sin ningún temor" cometía "continuos robos, frecuentes peleas y desgracias" en las narices del juez de paz que nada podía hacer, privado como estaba de un "piquete de vigilantes". ${ }^{79}$ Las dificultades para controlar a la

Argentinos que son enteramente pastores, seminómades por la vida salvaje y errante que llevan, tienen los instintos de las tribus del desierto..." (QUESADA, 1857, p.51.)

${ }^{77}$ Decreto 18-12-1863. R. O. P. C. Año 1863. Pp. 138-139. Los castigos eran ante la primera falta de trabajo en obras públicas durante treinta días y ante la segunda el servicio de las armas.

${ }^{78}$ El Progreso 31-07-1864. Hemeroteca. A. G. P. C.

79 “... V. E. se habrá penetrado del desorden en que han caído las masas de esta población con los continuos robos, las frecuentes peleas y desgracias que han sucedido desde tiempo anterior hasta hoy en la localidad. Para subordinar a una gente desordenada sin ningún temor, la autoridad necesita vigilar sobre ella desde muy cerca para no dejar escaparse los malvados de la acción del gobierno. Para establecerse pues esa vigilancia tan necesaria ya desde estos momentos, me permitiré suplicar al Gobierno se digne ordenar que el piquete de vigilantes destinados por el presupuesto para los Departamentos se plantee en esta Plaza lo más breve posible, si V. E. lo tiene a bien, o proveer de otra manera que lo encuentre más conveniente." Correspondencia Oficial. A. G. P. C. t. 197. F. 189. Bella Vista 28-04-1864. Saturnino Ramírez, juez de paz, al Excelentísimo Gobierno de la Provincia. 
clase menesterosa aumentaban proporcionalmente a la distancia en que se encontraran de los centros administrativos. Robustiano Lagraña, juez de paz de Curuzú Cuatiá, pedía al ministro de gobierno que proveyera alguna medida para combatir los males que producían los negocios en la campaña que no sólo eran los tratos fraudulentos, sino también los "focos de desorden y de inmoralidad" que generaban, volviendo inútiles todas las medidas contra el robo y la vagancia, por último, señalaba que su existencia ayudaba al aislamiento de los vecinos de la campaña “... privándoles del contacto con la parte más civilizada de la población... haciendo por estas circunstancias mucho más lento el adelanto material..."

La coacción extraeconómica no era la única alternativa que la clase principal tenía para conseguir mano de obra, otro recurso era el de "los pobladores" por medio del cual el propietario autorizaba a los campesinos a instalarse en sus tierras para que puedan producir lo necesario para su sustento, a cambio "el poblador" quedaba obligado a trabajar en las tareas de la estancia cuando el propietario así lo reclamase. (CHIARAMONTE, 1991, pp. 112-119) No obstante la población rural excedía largamente al número de "pobladores" y cometía innumerables e incorregibles perjuicios en las propiedades de la clase principal. ${ }^{81}$ Se buscó entonces arraigarlos en los ejidos de los pueblos, entregándoles, gratuitamente, suertes de chacras. (CASTELLO, 1985, p. 408) El Departamento de Caá Catí fue pionero en este procedimiento, fundando la colonia San Martín en las cercanías de dicha localidad. Su juez de paz al pedir autorización al Ministro de Gobierno explicaba las razones de la medida:

\begin{abstract}
"El Superior Gobierno sabe bien que en este Departamento como en todos los demás de la Provincia, hay innumerables familias proletarias que carecen absolutamente de recursos y de los elementos más indispensables para dedicarse al trabajo, viviendo por esta razón en la más completa holganza y sufriendo las consecuencias inevitables de la miseria más extremada; sabe también el Excmo. Gobierno, que esta triste condición de una gran parte de nuestras masas es un cáncer que aqueja dolorosamente a la sociedad, causándole males sin cuento, entre los que no es sin duda el menor, el obstáculo que opone al progreso de la riqueza pública, la inutilización de tantos brazos robustos y hábiles para concurrir al desarrollo de la industria y
\end{abstract}

\footnotetext{
${ }^{80}$ Correspondencia Oficial. A. G. P. C. t. 190. F. 76. Curuzú Cuatiá 21-09-1863. Robustiano Lagraña, juez de paz, al Ministro de Gobierno Juan José Camelino.

81 "Las continuas quejas de los hacendados de este Departamento sobre los perjuicios que sufren en sus intereses obligan al que suscribe a dirigirse a S. S. consultando de ser posible ordenar a algunas familias que viven en la campaña sin tener absolutamente de que vivir, el que viajen a este Pueblo, dándoles terrenos y medios para que se dediquen a la labranza que los mismos hacendados están dispuestos a proporcionar. Esta medida no sólo traería el bienestar de esas familias, que viven en la holgazanería y en la más completa ignorancia, sino que evitaría, en gran parte, los robos de ganado que con tanta frecuencia se repiten". Correspondencia Oficial. A. G. P. C. t. 197. F. 34. Curuzú Cuatiá 11-04-1864. Ramón Regunaga, juez de paz, al Ministro de Gobierno Juan José Camelino.
} 
con ella al bienestar y prosperidad general" 82

El gobierno provincial no sólo aprobó la medida sino que llamó a los demás jueces de paz a imitar al de Caá Catí. En 1864 las flamantes municipalidades auspiciaron prácticas similares, el consejo municipal de Mercedes al pedir la compra o expropiación de un terreno contiguo a la ciudad señalaba los beneficios de traer la población diseminada y pobre de la campaña “.... u un solo centro, en donde tengan a la vista la esperanza de un porvenir más cómodo y lucrativo, animados por el ejemplo de otros pueblos; y con la certeza de ser un día propietarios..." ${ }^{83}$ Las buenas intenciones de jueces y concejales estuvieron muy lejos de realizarse pues la política de tierras terminó siendo subsidiaria del fisco, situación que facilitó la formación de grandes propiedades, en detrimento de la clase menesterosa. ${ }^{84}$ Sin embargo para la década de 1860 todavía había mucha tierra pública. A esto debe agregarse el hecho de que ni el Estado ni el patrón podían obligar al pueblo llano a sufrir la disciplina del trabajo. El soberano todavía podía disfrutar del "ocio" y las elite de sus negocios prácticamente sin molestarse.

\title{
Consideraciones finales
}

El jefe del ejército de línea asentado en la capital provincial brindaba al presidente de la nación en octubre de 1863 una interesante descripción de la situación política correntina:

\begin{abstract}
“... en esta provincia reina un espíritu especial. Nuestros amigos están en muy reducido número, y estos mismos divididos entre sí, y en el fondo sólo son liberales hasta cierto punto. Aquí están vivos todavía los recuerdos de los pasados gobiernos y sus parciales en mayor que en cualquier otra parte de la República... en cualquier parte de ella creo más fácil la organización de un cuerpo que valga que en Corrientes, porque en esta provincia, la más envilecida y atrasada de la República, no creen nada posible sino está hecho en guaraní..." 85
\end{abstract}

\footnotetext{
${ }^{82}$ Correspondencia Oficial. A. G. P. C. t. 191. Fs. 4-7. Caá Catí 15-10-1863. Santos Insaurralde, juez de paz, al Ministro de Gobierno Juan José Camelino.

${ }^{83}$ Ibíd. T. 201. Fs. 136-137.

84 “Con la organización constitucional del país pudo reiniciarse la actividad constructiva. Desde mediados del siglo XIX hasta la última década de la centuria, la provincia experimentaría un notable crecimiento de su riqueza ganadera y surgirían los primeros atisbos de desarrollo agrícola. No obstante en este lapso se dilapidó la mayor parte del patrimonio fundiario del fisco. La ampliación de las responsabilidades del Estado, la pérdida de la fuente de renta que significaban las aduanas fluviales, el desorden administrativo, fruto en gran medida de las continuas luchas políticas, la ineficacia en la percepción de los gravámenes que pesaban sobre la riqueza privada, fueron entre tantas razones que impulsaron a las sucesivas administraciones, cualquiera fuera su signo político, a vender en condiciones cada vez más ventajosas los terrenos fiscales" (SCHALLER, 1986, p. 12).

${ }^{85}$ Corrientes 05-10-1863. Teniente Coronel Carlos Lezica a Bartolomé Mitre. ARCHIVO MITRE. Op. Cit. T. XXV, p. 201.
} 
Esta fue la realidad que debió enfrentar Manuel Ignacio Lagraña representante del mitrismo correntino, que luego de imponerse en la provincia se alió al "caudillaje de la campaña", según la acusación de los liberales de Goya. Esta alianza con los comandantes del sur provincial le dio la tranquilidad necesaria para dedicarse los dos primeros años de su gobierno al "adelanto material". La invasión paraguaya lo obligó a quitarse el overol y ponerse el uniforme de soldado para defender los principios que habían triunfado en Pavón.

Esos principios auguraban un futuro de felicidad al amparo de la constitución nacional, para ello había que dejar atrás las luchas intestinas y dedicarse a producir riquezas. Esta idea tan sencilla fue su norte y para concretarla utilizó todos los instrumentos que tuvo a su alcance.

Las páginas de El Progreso le permitieron pregonar su mensaje, "inmaculado" de política facciosa, que solamente promovía las "industrias útiles" y al mismo tiempo combatir contra La Esperanza y El Independiente para ganar el reducido tribunal de la opinión pública. Los preceptos liberales aparecen allí diáfanos y prontos a realizarse.

La instrucción de las masas era uno de ellos. El esfuerzo que se realizó en la materia fue reconocido en un informe de la década de $1870 .{ }^{1}$ Este empeño tenía como fin elevar a la "masa ignorante" a la altura de los "pueblos civilizados". Si bien era esta una política de largo plazo, el panorama era aciago. Escasos edificios, falta de útiles y carencia de personal idóneo.

Los juzgados de paz y las bisoñas municipalidades eran las instituciones que debían articular el pregón con la realidad, los contrastes eran evidentes. Jueces y concejales se vieron apremiados por las exigencias gubernamentales y la escasez de recursos para llevarlas a cabo. El adelanto material era algo en lo que todos estaban de acuerdo, pero a la hora de las concreciones aparecían discrepancias o sencillamente dificultades muchas veces insalvables.

Una de ellas era la apatía del pueblo llano que parecía imperturbable pues pasaba sus días a buen resguardo de la doble autoridad del Estado y del patrón. El gobierno no podía controlarlo y mucho menos obligarlo a producir riquezas y el mercado todavía no lo había proletarizado con sus manos invisibles.

El "decidido obrero" del mitrismo y la exigua administración provincial enfrentaron esa realidad en apariencia inmutable. Como tantos otros gobiernos dijeron maravillas e hicieron lo que pudieron, muchas veces las declaraciones quedaron muy lejos de las concreciones. Sin embargo su mensaje, el del crecimiento económico como el motor de la historia, triunfó plenamente y vería colmadas sus expectativas en el "granero del mundo", al menos las de su clase.

\footnotetext{
1 "La provincia de Corrientes recordará con gratitud los nombres del General Ferré, Pujol, Rolón, Lagraña y Guastavino como los infatigables obreros de la instrucción y la enseñanza a favor de sus ciudadanos." INFORME... Op. Cit. p. 94
} 


\section{Referencias bibliográficas}

Bonaudo, Marta y Zonzogni, Élida. 1999. "Los grupos dominantes entre la legitimidad y el control." En Nueva Historia Argentina. Liberalismo, Estado y Orden burgués (1852-1880). Dir. del tomo Marta Bonaudo. Bs. As., Editorial Sudamericana. T. 4. Cap. 1. Pp. 28-95.

Buchbinder, Pablo. 2004. Caudillos de pluma y hombres de acción. Estado y política en Corrientes en tiempos de la organización nacional. Bs. As., Prometeo libros. 174 pp.

Buchbinder, Pablo . 2005. "Estado y organización miliciana en Corrientes. Reflexiones sobre el caso de Nicanor Cáceres.” En XXV Encuentro de Geohistoria Regional. Corrientes, 25, 26 y 27 de agosto. (Inédito)

Castello, Antonio Emilio. 1984. Historia de Corrientes. Bs As., Editorial Plus Ultra. P. 403.

Chiaramonte, José Carlos. 1991. Mercaderes del litoral. Economía y Sociedad en la provincia de Corrientes, primera mitad del siglo XIX. Bs. As., F. C. E. 275 pp.

Fontana, Josep. La historia de los hombres. Trad. Ferrán Pontón. Barcelona, Crítica, 2001. 383 pp.

Gibelli, Nicolás J. (Dir.) 1968. Crónica Histórica Argentina. Bs. As., Ediciones Codex S. A. T. IV. 360 pp.

Gómez, H. F. 1922. Instituciones de la Provincia de Corrientes. Prólogo Juan Ramón Vidal. Bs. As., J. Lajoune \& Cía. Editores. 413 pp.

Halperín Donghi, Tulio. 1985. José Hernández y sus mundos. Bs. As., Editorial Sudamericana. $347 \mathrm{pp}$.

Mantilla, Manuel Florencio. 1887. Bibliografía Periodística de la Provincia de Corrientes. Bs. As., Imprenta y Librería de Mayo.

Méndez Paz, Emilio. 1953. Periódicos correntinos 1825-1900. Bs. As., Biblioteca Nacional. 123 pp.

Palti, Elías. Los diarios y el sistema político mexicano en tiempos de la República Restaurada (1867-1876). En Paula Alonso (compiladora). Construcciones impresas. Panfletos, diarios y revistas en la formación de los estados nacionales en América Latina, 1820-1920. Bs. As., FCE, 2004. pp. 167-181.

Puiggrós, Adriana. 2003. Que pasó en la educación argentina. Breve historia desde la conquista hasta el presente. Bs. As., Galerna. 219 pp.

Quesada, Vicente G. 1857. La Provincia de Corrientes. Bs. As., Imprenta de El Orden. 113 pp.

Ramírez Braschi, Dardo Rodolfo. 2005. "Descripción de la estructura estadual en los pueblos correntinos (1862-1863)". En XXV Encuentro de Geohistoria Regional. Corrientes, 25-26 y 27 de agosto. (Inédito).

Ramírez Braschi, Dardo Rodolfo. 2004. Orígenes de las Agrupaciones Electorales en la Provincia de Corrientes, de Caseros a las presidencias liberales. Corrientes, Moglia Ediciones. 229 pp.

Rosa, José María. 1979. Historia Argentina. La oligarquía (1862-1878). Bs. As., Editorial Oriente. T. $7.381 \mathrm{pp}$.

Ruiz Moreno, Isidoro J. 2000. “La política entre 1862-1880.” En Academia Nacional de la Historia. Nueva Historia de la Nación Argentina. Bs. As., Editorial Planeta. T. IV, pp. 453-481.

Schaller, E. C. 1998. "El gobierno de los centros urbanos y los distritos rurales y los distritos rurales de la provincia de Corrientes en la primera mitad del siglo XIX.” En Revista Nordeste. Segunda Época. Serie Investigaciones y Ensayos Nº 9 . Resistencia, Facultad de Humanidades UNNE. Pp. 41-62.

Schaller, E. C. 1986. "La adjudicación de las tierras fiscales (1821-1914)" En Todo es Historia. Cap. 5. Septiembre. Pp. 10-17. 
Schaller, E. C. 1995. La distribución de la tierra y el poblamiento en la provincia de Corrientes (1821-1860). Cuadernos de Geohistoria Regional n³1. Resistencia, I. I. G. H. I. Nordeste impresora. $277 \mathrm{pp}$.

Schaller, E. C. 2002. "Las finanzas públicas de Corrientes durante la organización constitucional (1851-1861).” En Revista Nordeste. Segunda Época. Serie Investigaciones y Ensayos. Historia no 16, septiembre. Resistencia. Pp. 5- 23.

Zimermann, Eduardo. 1998. "La prensa y la oposición política en la Argentina de comienzos de siglo. El caso de "La Nación” y el Partido Republicano." En Estudios Sociales, Revista universitaria semestral. Año VIII, nº 15, Santa Fe, Argentina, $2^{\circ}$ semestre. Pp. 45-70.

\section{Fuentes éditas}

Archivo del General Mitre. Bs. As, Biblioteca de "La Nación”, 1912 (13). Tomos XII y XXV. Gómez, Hernán Félix. Diccionario Biográfico. Archivo General de la Provincia de Corrientes. Informe acerca de la Provincia de Corrientes Presentado a la Comisión de la Exposición Nacional de Córdoba, por Cecilio Echeverría y Ramón Contreras. En: Boletín Oficial de la Exposición Nacional de Córdoba en 1871. Vol. $6^{\circ}$, Serie de Memorias № 2. Bs. As., Imprenta, litografía, fundición de tipos a vapor de la Sociedad Anónima 126-Belgrano-126, 1873. Pp. $1-114$.

Periódico "El Progreso" (1863-1865). Archivo General de la Provincia de Corrientes. Hemeroteca.

Registro Oficial de la Provincia de Corrientes. Años 1863, 1864,1865, 1866. Archivo General de la Provincia de Corrientes.

República Argentina. Primer Censo de la República Argentina. Bs. As., El Porvenir, 1872.

\section{Fuentes inéditas}

Fondo Mantilla. Archivo Pampín. Legajos No 47. (1861-1862) y No 17 (1862-1879). Archivo General de la Provincia de Corrientes.

Correspondencia Oficial. TT. 183-212. Archivo General de la Provincia de Corrientes. 